\title{
SILVA, Uiran Gebara da. Rebeldes Contra 0 Mediterrâneo: Revoltas rurais e a escrita da história das classes subalternas na Antiguidade Tardia. São Paulo: FAPESP Humanitas, 2016. 414 p. ${ }^{1}$
}

\author{
Pedro Luís de Toledo Piza²
}

Fruto de um produtivo trabalho de pesquisa visando o doutoramento em História Social pela Universidade de São Paulo, creio que a obra de Uiran Gebara da Silva possa ser sintetizada em duas palavras: indignação e resgate. Indignação, porque o autor apresenta constantemente a falha da historiografia sobre o mundo rural tardo-antigo em ver o que, a partir de sua análise, se mostra óbvio: que existem pelo menos dois movimentos populares, compostos sobretudo de trabalhadores e pequenos proprietários rurais, que se organizam como questionamento ao ordenamento social do qual eram parte. São eles conhecidos como "circunceliões" e "bagaudas", os primeiros agindo no norte da África, e os outros em uma área pouco definida entre a Tarraconense e a Armórica. Resgate, porque, a partir da identificação da sobredita deficiência historiográfica, o autor se propõe a iniciar uma nova corrente de pesquisas a respeito dos referidos movimentos, tendo sua origem social e seus objetivos mais esclarecidos a partir de uma análise comparativa entre ambos.

Por conta disso, justifica-se o subtítulo dado ao trabalho final: "Revoltas rurais e a escrita da história das classes subalternas na Antiguidade Tardia". De fato, muito mais do que uma mera narrativa ou proposta analítica acerca dos circunceliões e bagaudas, com suas respectivas origens, objetivos e formas de ação coletiva, Uiran Gebara se dedica a entender o porquê de tais grupos terem sido enxergados de maneiras diversas pela maior parte da historiografia (como braços armados de potentados locais, monges fanáticos, revoltosos nativistas, etc.) do século $\mathrm{XX}$, menos como mobilizações de trabalhadores rurais (com a possível presença de escravos aí incluída, ainda que não certa) e pequenos proprietários. Isso explica porque boa parte de sua obra é dedicada à

\footnotetext{
1 Sou profundamente grato a Camila Aline Zanon pelo trabalho de revisão ortográfica.

2 Mestre em História, Universidade de São Paulo, São Paulo, Brasil. email: pl_piza@hotmail.com
} 
discussão teórica e historiográfica tanto sobre a pesquisa mais restritamente voltada para os dois movimentos revoltosos, quanto sobre o campo, a produção rural e as relações de trabalho na Antiguidade Tardia. Frente a tal debate muito profícuo e que tem muito a nos dizer sobre o próprio século XX, a análise final, onde o autor se debruça de fato sobre a documentação (como sempre, oriunda de elites que servem de filtro para a informação a respeito de seus subalternos), aparece mais como uma proposta visando estimular mais pesquisas sobre o mesmo tema do que exatamente uma exposição definitiva a seu respeito. Certamente, essa é uma das maiores virtudes a serem destacadas em seu trabalho.

Por conta de sua disposição em criticar a maior parte das pesquisas sobre as relações sociais no campo na Antiguidade Tardia envolvendo bagaudas e circunceliões, o autor dedica todo o primeiro capítulo à apresentação e problematização da historiografia com a qual debate. $\mathrm{O}$ ponto central nessa parte é a elucidação dos pressupostos teóricos a respeito do ambiente rural tardo-antigo presentes em concepções do que consistiriam os dois movimentos abordados pela pesquisa. Uiran Gebara apresenta como modelo explicativo básico de tais leituras aquele que define as relações sociais no campo como fundamentalmente marcadas por uma queda na qualidade de vida do campesinato no mesmo compasso de uma ascensão do patronato rural, que ganharia expressão legal na instituição do colonato, a qual deveria ser considerada a base do feudalismo medieval. Nesse sentido, a autonomia dos camponeses participantes dos movimentos investigados é severamente rebaixada em prol de uma leitura voltada para a identificação de relações patronais nos mesmos. A consequência é a tendência em ler os bagaudas como meros braços armados de potentados rurais com traços caudilhescos, e os circunceliões como grupos de religiosos fanáticos reunidos por bispos donatistas no contexto da principal querela cristã norte-africana dos séculos IV e V d.C.

No entanto, Uiran Gebara se propõe a fazer uma leitura diferente dos dois fenômenos históricos. Não pretende lê-los como simples braços de potentados locais, como se fossem mera massa de manobra, mas sim como camponeses compondo uma classe subalterna no espectro social da Gália, da Hispânia e do norte da África tardo-antigos. Contudo, em sociedades nas quais o grosso do material literário é produzido pelas classes dominantes, obviamente tal abordagem histórica defronta-se com limitações severas. O segundo capítulo é dedicado à identificação dessas limitações e às opções teórico-metodológicas à disposição do historiador para driblá-las. 
Se o capítulo 2 aborda questões teórico-metodológicas para a análise de documentação sobre o campesinato oriunda das classes dominantes, o terceiro capítulo passa para a práxis. O objetivo do autor aqui é demonstrar que os autores antigos tendem a apresentar os dois movimentos de forma muito semelhante em vários aspectos. Para tanto, Uiran segue basicamente por dois caminhos, ainda que nem sempre tão delimitados entre si: por um lado, procura explicitar que existem certos topoi literários generalizadamente presentes em narrativas acerca de momentos de empoderamento real (via rebelião) ou simbólico de classes subalternas (sendo os topoi três: a inversão de autoridade, a Era de Ouro igualitária e a reversão das linhas de autoridade) e como eles são utilizados para tratar dos movimentos analisados; por outro, busca esclarecer que, diferentemente do que seria a preferência da maior parte da historiografia, não existe uma tendência geral da documentação em se referir a bagaudas e circunceliões como latrones, o que poderia ser um indicativo de sua vinculação a potentados locais por meio de relações patronais. Possivelmente, a principal conclusão da análise documental do terceiro capítulo seja a de que o patronato rural, longe de se encontrar em plena ascensão (como defendia a maior tendência historiográfica da segunda metade do século XX), aparentemente enfrentava uma crise em sua hegemonia, crise esta da qual a existência de movimentos contestadores como os bagaudas e circunceliões surgem como exemplos sintomáticos.

A esse questionamento dos modelos o autor retorna no quarto capítulo. Nele, Uiran Gebara visa esclarecer as origens sociais dos revoltosos estudados, a saber, as comunidades rurais da Gália, da Hispânia e do norte da África. Também aqui ele se move em dois sentidos de análise: primeiro, faz uma confrontação historiográfica entre modelos, destacando-se dentre eles o de Chris Wickham, sobretudo por sua utilização atualizada de toda a pesquisa arqueológica rural voltada para a Antiguidade Tardia e por seu questionamento da predominância do patronato rural e da difusão generalizada do colonato em todas as regiões do Mediterrâneo; segundo, apresenta a caracterização feita dos bagaudas e dos circunceliões por fontes mais ou menos contemporâneas aos eventos, assim como os objetivos e interesses por trás de tais narrativas. Neste sentido, por exemplo, as informações dadas por Agostinho de que os circunceliões agonísticos seriam basicamente os braços armados dos bispos donatistas são questionadas, tendo-se em conta o interesse do autor antigo em difamar seus adversários seguidores do donatismo, ignorando tanto que houvesse conflitos registrados entre ambos, quanto que circunceliões atuassem por vezes com anuência de bispos do mesmo grupo do bispo de Hipona. 
Por fim, no quinto capítulo, o autor retorna à documentação, desta vez para propor uma nova narrativa acerca das ações de bagaudas e circunceliões, tendo como pano de fundo a atualização historiográfica e a análise da caracterização literária dos movimentos, com o objetivo de elucidar seus métodos, área de ação e objetivos. A partir de tal análise, Uiran Gebara propõe um novo modelo explicativo acerca desses dois fenômenos sociais, "que vê um processo de politização das relações sociais no campo quando as formas tradicionais de dominação ideológica e política entraram em crise" (p. 276). Bagaudas e circunceliões não são mais exemplos da ascensão contínua do poderio e patronato de potentados locais, em um processo que desemboca no feudalismo e na servidão medievais, mas sim sintomas da crise de hegemonia de tais grupos, a qual permite que movimentos populares de contestação política (sem liderança centralizada aparente, outro dado relevante trazido à tona pelo autor) se organizem e lutem por seus anseios e interesses, com um possível exemplo notável de sucesso relativamente duradouro podendo ser identificado no caso da Armórica, cujos habitantes passam a ser, em alguns documentos, referidos dentre os bárbaros, por terem abandonado a ordem romana (uma possível referência à demolição do ordenamento ideal romano de propriedade da terra e exploração do trabalho).

Notoriamente, um dos pontos mais fascinantes da obra de Uiran Gebara da Silva é sua natureza política, para além da mera pesquisa acadêmica bem feita. O próprio autor explicita ser este o caso (ou devendo ser) não apenas de seu trabalho, mas de toda pesquisa que se volte para a história das classes subalternas. No caso de Rebeldes contra o Mediterrâneo, a politização se volta, a meu ver, para as duas palavras destacadas no início da resenha. Por um lado, a indignação, não como um simples sentimento de inconformidade com uma tendência estabelecida, mas sim como um posicionamento acadêmico e científico consciente de crítica permanente da produção historiográfica que sirva ou reflita o status quo de seu tempo. Nesse sentido, nada mais representativo do que as próprias palavras do autor em sua conclusão: “... mas a grande descoberta que fiz com essa pesquisa é que, no que diz respeito à história dos de baixo, mais obscurecedora do que os autores antigos é a ação dos historiadores do fim do século XX, mais simpáticos às injustiças do Império Romano do que alguns membros da própria elite romana" (p. 277). Por outro lado, o resgate, fruto de tal indignação e oriundo de um posicionamento político que olha mais para as capacidades e a agência dos "de baixo" do que para o fantástico (e, por vezes, "moderno") aparato de dominação por parte das elites romanas, a ponto de não ser possível encarar os dois grupos de revoltosos como algo além de turbas manipuladas por poderosos. Como consequência, o claro resultado da pesquisa de Uiran Gebara da Silva 
possui certo aroma de obviedade, devido norteamento lógico que guia todo o trabalho. No entanto, são justamente as obras que explicitam o óbvio contra todos os esforços em ignorá-lo que merecem ser consideradas obras-primas. 